OPEN ACCESS

Edited by:

Andrea S. Aspbury,

Texas State University, United States

Reviewed by:

Mary E. Ramsey,

The University of Texas at Austin

United States

Ana Ruiz-Navarro,

University of Murcia, Spain

*Correspondence:

Kit Magellan

kitmagellan@gmail.com

${ }^{\dagger}$ Present address: Kit Magellan,

University of Battambang,

Battambang, Cambodia

Specialty section:

This article was submitted to Behavioral and Evolutionary Ecology,

a section of the journal

Frontiers in Ecology and Evolution

Received: 26 December 2020

Accepted: 22 March 2021

Published: 26 April 2021

Citation:

Magellan K and García-Berthou E (2021) Prioritizing Sex Recognition Over Learned Species Recognition: Hierarchical Mate Recognition in an

Invasive Fish.

Front. Ecol. Evol. 9:646357. doi: 10.3389/fevo.2021.646357

\section{Prioritizing Sex Recognition Over Learned Species Recognition: Hierarchical Mate Recognition in an Invasive Fish}

\author{
Kit Magellan ${ }^{\star+}$ and Emili Garcia-Berthou \\ Institute of Aquatic Ecology, University of Girona, Girona, Spain
}

Mate recognition is the process of identifying and assessing the appropriate species, sex or population of another individual for their suitability as a potential mate. Recognition may be innate or learned. Learning, the acquisition of knowledge or skills through experience, involves a relatively long-term change in behavioral responses. In this study we examined learned and innate mate recognition in invasive male mosquitofish, Gambusia holbrooki, interacting with female conspecifics and male and female native toothcarp, Aphanius iberus. Male mosquitofish directed no mating attempts at male toothcarp whereas numerous attempts were made toward female toothcarp. Male mosquitofish therefore differentiated between males and females, but initially did not distinguish between con- and heterospecific females. Neither the presence of a male toothcarp, nor the presence of a refugia affected the number of mating attempts received by females. However, by the second day males appeared to learn to more accurately direct their mating attempts, with larger female mosquitofish receiving the most attention, though smaller toothcarp females were still harassed. We propose that male mosquitofish, with a coercive mating system, are selected for persistence despite rejection by potential mates. In this scenario, the pool of potential mates may include heterospecifics whose avoidance of mating attempts may be ignored by male mosquitofish. It may thus be adaptive for male mosquitofish to prioritize sex recognition over species recognition: if one sex is recognized as a "non-mate" this will cut $50 \%$ from the pool of potential mates whereas recognition of a single species will remove many fewer potential mates from the pool. This innate sex recognition together with rapid learning of species identity may be a factor in the invasive success of mosquitofish.

Keywords: behavior, biological invasions, mosquitofish, toothcarp, Gambusia, Aphanius

\section{INTRODUCTION}

Mate recognition is the process of identifying and assessing another individual for their suitability as a potential mate (Ryan and Rand, 1993; Pfennig, 1998; Mendelson and Shaw, 2012) and can be applied to recognition of an individual of the appropriate species, sex, or population (Ryan and Rand, 1993). Mate recognition is part of a process in which an individual is identified as a compatible mate (mate recognition), and assessed for quality with respect to the potential fitness 
benefits that may be conferred relative to other compatible mates (mate preference) (Ryan and Rand, 1993; Pfennig, 1998; Mendelson and Shaw, 2012). Individuals may use multiple traits to assess potential mates (Pfennig, 1998; Candolin, 2003; Mendelson and Shaw, 2012) and different traits may be involved in mate recognition and mate preference (Pfennig, 1998).

Learning, the acquisition of knowledge or skills through experience, is widespread in nature. It involves a change in behavioral responses, which should be neither transient (changing with almost every presentation of a stimulus) nor permanent (once knowledge or skill has been learned it is unchangeable), but must have at least the capacity to change. Learning may be individual or trial-and-error (i.e., learning through experience), or social (i.e., learning from others) (Galef and Laland, 2005; Campobello and Sealy, 2011). The requirements for learning may change throughout an individual's life. For example, learning to recognize predators is critical at all life stages so should be learned at the earliest opportunity. On the other hand, learned mate recognition does not become essential until sexual maturity, although interestingly mate recognition may be facilitated early in development through sexual imprinting (e.g., Irwin and Price, 1999; ten Cate and Rowe, 2007; Verzijden et al., 2012). However, recognition may be innate or learned (Kamo et al., 2002), and often both processes are incorporated into recognition of a single type of stimulus (e.g., Epp and Gabor, 2008; Milet-Pinheiro et al., 2012; Mueller et al., 2013). If recognition is innate, all (or most) members of a species or population will share the same recognition ability, whereas if recognition is learned, each individual must undertake the learning process so recognition abilities will vary between individuals. Learned recognition is therefore more likely to be subject to recognition mistakes (Kamo et al., 2002).

In this study we examined learned mate recognition through the interactions between invasive mosquitofish, Gambusia holbrooki, and native toothcarp, Aphanius iberus. Among invasive species, the Poeciliid G. holbrooki (and the closely related Gambusia affinis) are perfect models for this type of investigation. This native of North America (Parenti, 1981) has been introduced to all continents except Antarctica for mosquito control (Lever, 1996; García-Berthou et al., 2005; Pyke, 2008), so encountering many novel situations, and has subsequently successfully adapted to and colonized new habitats (e.g., Pyke, 2008; Benejam et al., 2009). Indeed, they are considered to be among the 100 worst invasive species worldwide (Lowe et al., 2000). One factor in their invasion success may be their rapid learning ability (Magellan et al., 2019). Moreover, the relatively recent contact between mosquitofish and toothcarp (since 1921 or later, García-Berthou et al., 2005; Benejam et al., 2009) suggests that, unless invasion has induced rapid selection for adaptive recognition (Strauss et al., 2006; Sih et al., 2010), recognition mechanisms are unlikely to have developed (Sherman et al., 1997; Payne et al., 2004).

Although both mosquitofish and toothcarp are Cyprinodontiform fishes (Parenti, 1981) these species differ in several respects. In contrast to the wide mosquitofish distribution, the toothcarp is endemic to the Iberian Peninsula (Ruiz Navarro and Oliva Paterna, 2012) and is classed as endangered and decreasing under the IUCN Red List and by the
Bern Convention on the Conservation of European Wildlife and Natural Habitats (Freyhof and Brooks, 2011). For example, at the last count, of the 38 original Mediterranean populations 15 were known to be extinct (Doadrio, 2002) and this situation is likely to have worsened. In addition, while both species are sexually dimorphic (mosquitofish: Meffe and Snelson, 1989; Evans et al., 2011; toothcarp: Ruiz Navarro and Oliva Paterna, 2012), mosquitofish have internal fertilization and live birth (Meffe and Snelson, 1989) while toothcarp is an egg-laying species with external fertilization (Ruiz Navarro and Oliva Paterna, 2012) precluding the possibility of hybridization between these two species. However, as both sex and species recognition is necessary for successful copulation, these species provide the interesting prospect of investigating the potential for learning of different aspects of recognition.

Our aims were threefold. First, as male mosquitofish are voracious in pursuit of mating opportunities (Meffe and Snelson, 1989; Evans et al., 2011), and we are interested in the mechanisms by which invasive mosquitofish impact on native species, we examined male mosquitofish mate recognition ability. We predicted that mosquitofish males would attempt to mate preferentially with their own species and would be able to distinguish between sexes such that any misdirected mating attempts would be mainly toward female toothcarp. Second, we evaluated three alternative hypotheses for male mosquitofish mating preferences: (i) as larger female poeciliids are more fecund (Meffe and Snelson, 1989; Evans et al., 2011), and therefore should be preferred (Andersson, 1994), male mosquitofish would attempt to mate preferentially with larger females of either species; (ii) that the extent of harassment experienced by female toothcarp would depend on whether a companion toothcarp was male or female; and (iii) that females of either species would be able to use a refuge to escape male harassment (e.g., Magellan and García-Berthou, 2016), i.e., that male mosquitofish mating preferences are a function of female availability. Finally, we investigated male mosquitofish capacity to learn mate recognition predicting that male mosquitofish would be able to direct their mating attempts more accurately within a short time scale.

\section{MATERIALS AND METHODS}

Fish were collected, using dip nets, from the Ter $\left(42.0451^{\circ} \mathrm{N}\right.$, $\left.3.1960^{\circ} \mathrm{E}\right)$, Fluvià $\left(42.1875^{\circ} \mathrm{N}, 3.0851^{\circ} \mathrm{E}\right)$, and Muga $\left(42.2527^{\circ} \mathrm{N}\right.$, $3.0756^{\circ} \mathrm{E}$ ) rivers (mosquitofish) and from Fra Ramon lagoon $\left(42.0149^{\circ} \mathrm{N}, 3.1129^{\circ} \mathrm{E}\right)$, Baix Empordà salt marshes (toothcarp). The mosquitofish from these populations had no prior contact with toothcarp and while toothcarp individuals may have previously encountered mosquitofish this contact was minimal. Fish were transported to the laboratory and placed in six $60 \mathrm{~L}$ species-specific (three per species) stock tanks $(60 \times 30 \times 32 \mathrm{~cm})$. Mosquitofish from all three rivers were housed together. Each tank contained a gravel substrate, conditioned water and a filtered air supply. Tanks were illuminated with $6 \mathrm{~W}$ bulbs and maintained at a constant photoperiod $(12: 12 \mathrm{~h}$ light:dark cycle) and temperature $\left(25 \pm 1^{\circ} \mathrm{C}\right)$. Fish were fed to 
satiation once per day with commercial food flakes or frozen bloodworms (Chironomus spp.). Fish were allowed to acclimate to laboratory conditions for at least 2 months prior to the start of experimentation.

The experiment was conducted in six $26 \mathrm{~L}$ tanks $(45 \times 22 \times 28 \mathrm{~cm})$, each containing a gravel substrate, an air supply, an aquarium heater and water filled to a depth of $20 \mathrm{~cm}$. A light source was positioned above each tank. The evening before a set of observations, six pairs of toothcarp were selected at random with the proviso that at least one was a female and that they could be easily identified. In cases where there were two females this meant that one was larger than the other. This resulted in 10 female-female toothcarp pairs and 13 female-male pairs. One pair of fish was added to each of the experimental tanks, fed, and left overnight to acclimate. The following morning six sets of one male and one female mosquitofish were selected at random and added to the experimental tanks. A refuge, consisting of a clear plastic jar, $5 \mathrm{~cm}$ diameter and $12.5 \mathrm{~cm}$ tall covered with a gray mesh, was added to half of the tanks (treatment B: refugia). The refugia were oriented so that the open end faced the front of the tank. The other three tanks were left without refugia (treatment A: control).

All fish were fed and left for $1 \mathrm{~h}$ after which 10-min observations were conducted. All observations were videoed and scored later. After each trial, a refuge was added (treatment A) or removed (treatment B) as required. Fish were again left for $1 \mathrm{~h}$ to acclimate, after which a second 10-min observation was carried out as before. The order of treatments A and B was thus randomized. At the end of all trials for a day, refugia were added to each of the tanks as needed, and fish were again fed and left overnight. The following morning fish were fed and left for $1 \mathrm{~h}$ as before and the 10-min trials (treatment C: day 2, with refugia) were videoed. After all trials, total length (measured to the nearest millimeter using a ruler) and sex of each fish were recorded and fish were placed in separate stock tanks so that they would not be reused. In total 23 sets of fish were observed in all three treatments.

Each video was analyzed recording the number of mating attempts directed at each individual in a group by the male mosquitofish and the time each fish spent in the refugia. Male mosquitofish mating attempts were defined as a gonopodial thrust, with or without a preceding chase. For statistical analyses the female in male-female toothcarp pairs or the larger female in female-female pairs was designated T1 (i.e., toothcarp 1). The second toothcarp in each group was designated $\mathrm{T} 2$ and the female and male mosquitofish were designated M1 and M2, respectively.

First the difference in total length between T1 and M1 in each group of fish was assessed using a paired $t$-test.

Then, mating attempts received from the mosquitofish male were examined in three analyses. As toothcarp 2 (T2) received no or very few mating attempts (see section "Results") this data set was excluded from analyses and only the mating attempts received by $\mathrm{T} 1$ and $\mathrm{M} 1$ were included. For these analyses we used Generalized Estimating Equations (GEEs), an extension of Generalized Linear Models developed for situations where response variables are nonindependent, to account for the within-subjects factors (e.g.,
Magellan and García-Berthou, 2015). For all analyses, fish group was the experimental unit (i.e., the two toothcarp and two mosquitofish that were examined together) and the dependent variable, frequency of mating attempts received, was analyzed with Poisson distribution and a log-link function. First, to assess the influence of the species and length of females, and the capacity of male mosquitofish to learn mate recognition (i.e., the effect of treatment) on the number of mating attempts received, the analysis comprised two within-subjects factors (treatment and species) and one covariate (female length) as the independent variables. Second, as examination of graphs showed a large difference between treatments $\mathrm{A}$ and $\mathrm{B}$ and treatment $\mathrm{C}$ (see Figure 1), the data from the second day was examined separately using one within-subjects factor (female species) and one covariate (female length). Third, the effect of the presence of a male toothcarp (i.e., when $\mathrm{T} 2$ was male) on the frequency of mating attempts received by T1 was assessed using mating attempts received by $\mathrm{T} 1$ as the dependent variable, with one within-subjects factor (treatment) one between subjects factor (T2 sex) and one continuous factor (T1 length).

Finally, the potential effects of the presence of a refuge were examined. As these data were zero inflated, non-parametric analyses were used. First the data for time spent in refugia by each individual were collapsed across each independent variable of interest and differences were assessed using Wilcoxon signed rank tests for the related data sets (time and species) and a Mann-Whitney $U$-test for differences between sexes. Then the relationships between refugia use and mating attempts received were assessed using separate Spearman rank correlations for the females of each species (i.e., T1 and M1) on each day.

\section{RESULTS}

In the assessment of female size, the female mosquitofish were significantly longer than the (larger) female toothcarp in each group (T1: $31.0 \pm 2.56 \mathrm{~mm}, \mathrm{M} 1: 36.7 \pm 4.61 \mathrm{~mm}$, mean \pm s.d.; paired- $\left.t_{(22)}=-4.85, p<0.001\right)$.

All but three of the male mosquitofish attempted to mate in at least one of the treatments. The vast majority of mating attempts were directed at the female or larger female toothcarp (T1) and the female mosquitofish (M1). No male toothcarp received any mating attempts from the male mosquitofish in any of the trials while only three of the small females in the female-female toothcarp pairs received a single mating attempt.

Importantly there was no difference between female mosquitofish and female toothcarp in the frequency of mating attempts received (Table 1: Analysis 1). However, there was a significant difference between treatments in the frequency of mating attempts received (Table 1: Analysis 1). Moreover, while female length itself showed no significant pattern there was a significant interaction between length and treatment, with larger females receiving more mating attempts, particularly on day 2 (Treatment C) (Table 1: Analysis 1, Figure 1).

When data from day 2 were considered separately the relationships between species were modified. There was a significant interaction between species and length of females. 

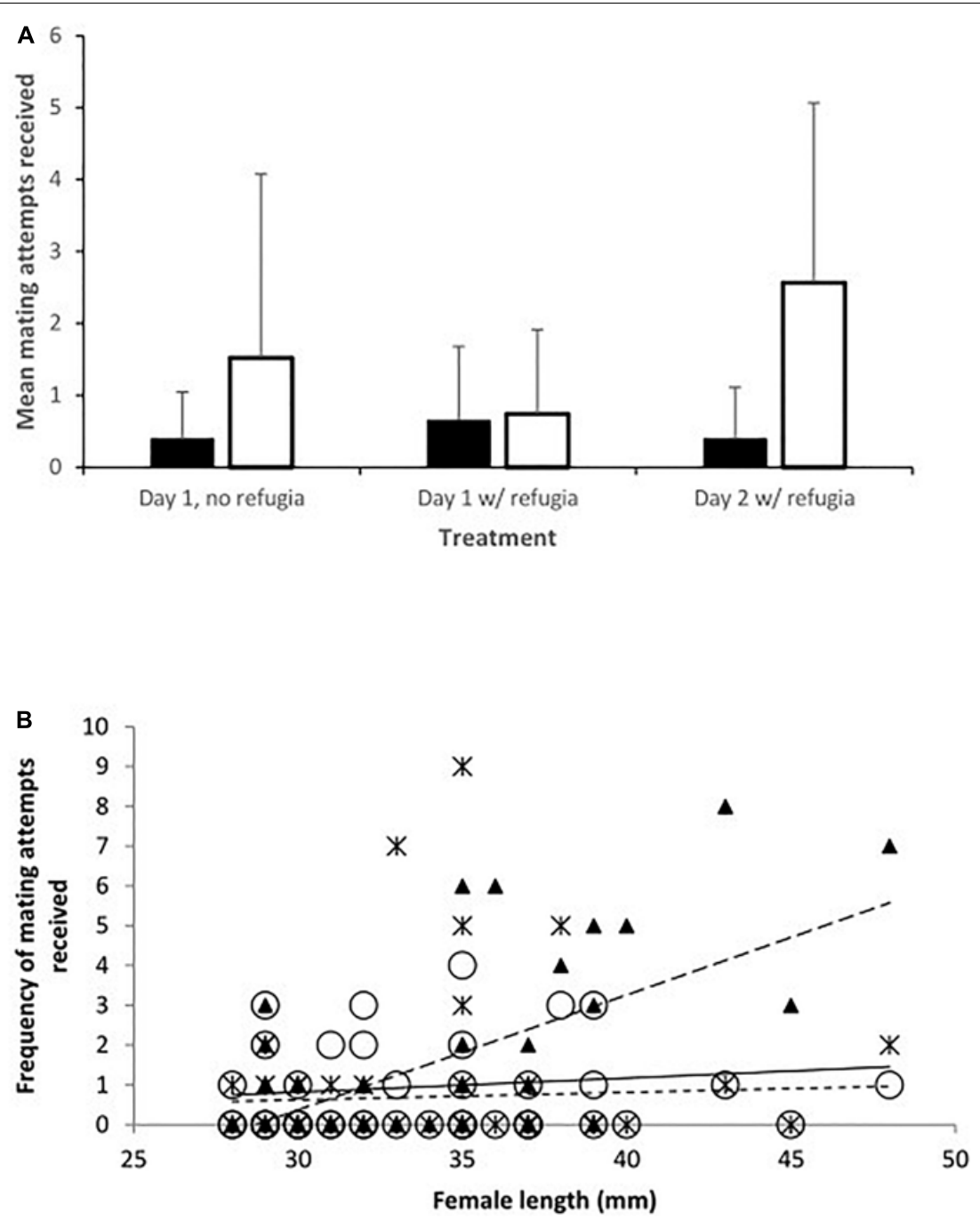

FIGURE 1 | (A) Mean mating attempts received by toothcarp (black bars) and mosquitofish (white bars) females from mosquitofish males. Error bars show standard deviation; and (B) The frequency of mating attempts received by mosquitofish and toothcarp females combined in relation to their total length. Trendlines have been added for illustration. Treatment A: black crosses, solid line; B: white circles, small dashed line; C: black triangles, large dashed line.

The frequency of mating attempts received increased with female size for mosquitofish, but for toothcarp females mating attempts received showed a slight decline with increasing length (Table 1: Analysis 2, Figure 2). Although the main effect of species was still not significant a trend in species differentiation was apparent (Table 1: Analysis 2).

When considering the effect of the presence of a male T2, the sex of the conspecific individual (T2) showed no significant effect and treatment was likewise not significant (Table 1: Analysis 3). However, the frequency of mating attempts across all treatments decreased significantly with increasing length of T1 (Table 1: Analysis 3, Figure 3).

Fish of both species and sexes entered refugia although use was overall limited with only 15 of the 23 trials on day 1 and $14 / 23$ on day 2 including any refugia use. While both con- and heterospecific fish used refugia concurrently on occasion, in most trials in which refugia use occurred only one of the four fish entered ( 1 fish: 19 out of 46 trials; 2 fish: 9/46; 3 fish: 1/46; 4 fish: 0/46). Refugia use did not vary between sexes $(Z=-0.252$, $p=0.801$; Figure 4) or between days $(Z=-0.692, p=0.489$; Figure 4), though toothcarp made greater use of refugia than mosquitofish $(Z=-3.894, p<0.001$; Figure 4). In addition, there was no relationship between refugia use and mating attempts received by females of either species on either day (Day 1: toothcarp: $r=0.089, p=0.686$, mosquitofish: $r=-0.165$, $p=0.451$; Day 2: toothcarp: $r=-0.192, p=0.381$, mosquitofish: $r=-0.215, p=0.324)$.

\section{DISCUSSION}

Male mosquitofish were evidently able to differentiate between males and females. In the $15 \mathrm{~h}$ of observations analyzed for this study no mating attempts were directed at male toothcarp 
TABLE 1 | Results from the three Generalized Estimating Equations.

\begin{tabular}{|c|c|c|c|}
\hline Variable & Wald $\chi^{2}$ & df & $p$ \\
\hline \multicolumn{4}{|c|}{ Analysis 1: Both species, Day 1 and 2} \\
\hline Treatment (T) & 8.106 & 2 & 0.017 \\
\hline Species (Sp) & 0.309 & 1 & 0.578 \\
\hline Length (L) & 0.754 & 1 & 0.385 \\
\hline $\mathrm{T} \times \mathrm{Sp}$ & 1.686 & 2 & 0.430 \\
\hline$T \times L$ & 10.956 & 2 & 0.004 \\
\hline$S p \times L$ & 0.738 & 1 & 0.390 \\
\hline$T \times S p \times L$ & 3.533 & 2 & 0.171 \\
\hline \multicolumn{4}{|c|}{ Analysis 2: Both species, Day 2 only } \\
\hline Species (Sp) & 3.454 & 1 & 0.063 \\
\hline Length (L) & 0.355 & 1 & 0.551 \\
\hline$S p * L$ & 4.949 & 1 & 0.026 \\
\hline \multicolumn{4}{|c|}{ Analysis 3: Toothcarp only, Day 1 and 2} \\
\hline Treatment $(T)$ & 4.487 & 2 & 0.106 \\
\hline T2 Sex (Sx) & 0.435 & 1 & 0.510 \\
\hline T1 Length (L) & 5.741 & 1 & 0.017 \\
\hline$T \times S x$ & 3.197 & 2 & 0.202 \\
\hline$T \times L$ & 4.452 & 2 & 0.108 \\
\hline$S x \times L$ & 0.357 & 1 & 0.550 \\
\hline$T \times S x \times L$ & 2.555 & 2 & 0.279 \\
\hline
\end{tabular}

Analysis 1: the effects of treatment, species, and total length of females on the frequency of mating attempts received by females of both species; Analysis 2: the effects of species and female length on the number of mating attempts received by females of both species on the second day; Analysis 3: the effects of treatment, conspecific sex, and female length on the frequency of mating attempts received by toothcarp 1. Significant results are highlighted.

whereas numerous attempts were made toward female toothcarp. However, male mosquitofish initially did not distinguish between con- and heterospecific females. Our alternative hypotheses to explain the relative frequency of male mosquitofish mating attempts also received limited or no support. First, although female mosquitofish were larger, and overall larger females were preferred, the exact relationship between male mosquitofish mating attempts and female size depended on both species and time. Male mosquitofish harassed smaller toothcarp females more than larger females, whereas the reverse was true for mosquitofish females, but this did not become notable until the second day. The exact role of female length in male mosquitofish mating preferences in the current study is therefore unclear. Second, whether the second toothcarp was male or female made no difference to the frequency of mating attempts received by female toothcarp, indicating that male mosquitofish did not divide their efforts between all the available females; that neither male nor female presence provides an adequate deterrent or stimulus; and that mate guarding, or other forms of aggression, from male toothcarp are absent or at least ineffective against male mosquitofish. Third, the presence or absence of refugia made no difference to mating attempts received by females, implying that females of neither species used refugia to escape male attention. This is in contrast to previous work in which toothcarp appeared to utilize refugia to escape aggression from mosquitofish (Magellan and García-Berthou, 2016). However, in this case it is clear that male mosquitofish mating attempts are not a function of female availability.

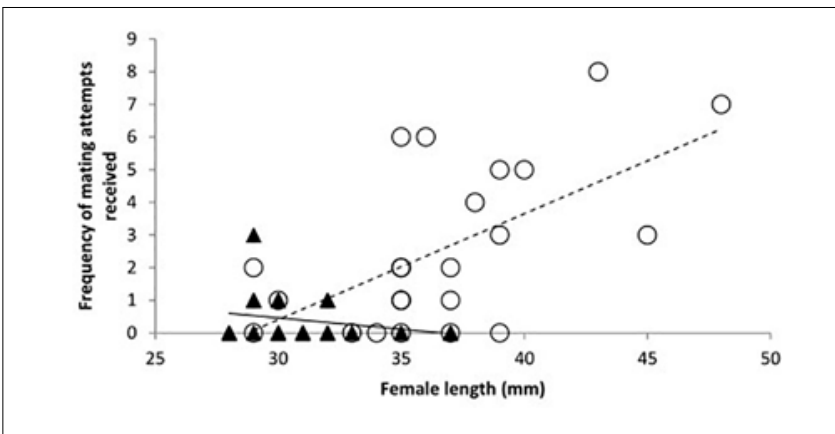

FIGURE 2 | The frequency of mating attempts received by females on day 2 in relation to their total length. Trendlines have been added for illustration. Toothcarp: black triangles, solid line; mosquitofish: white circles, small dashed line.
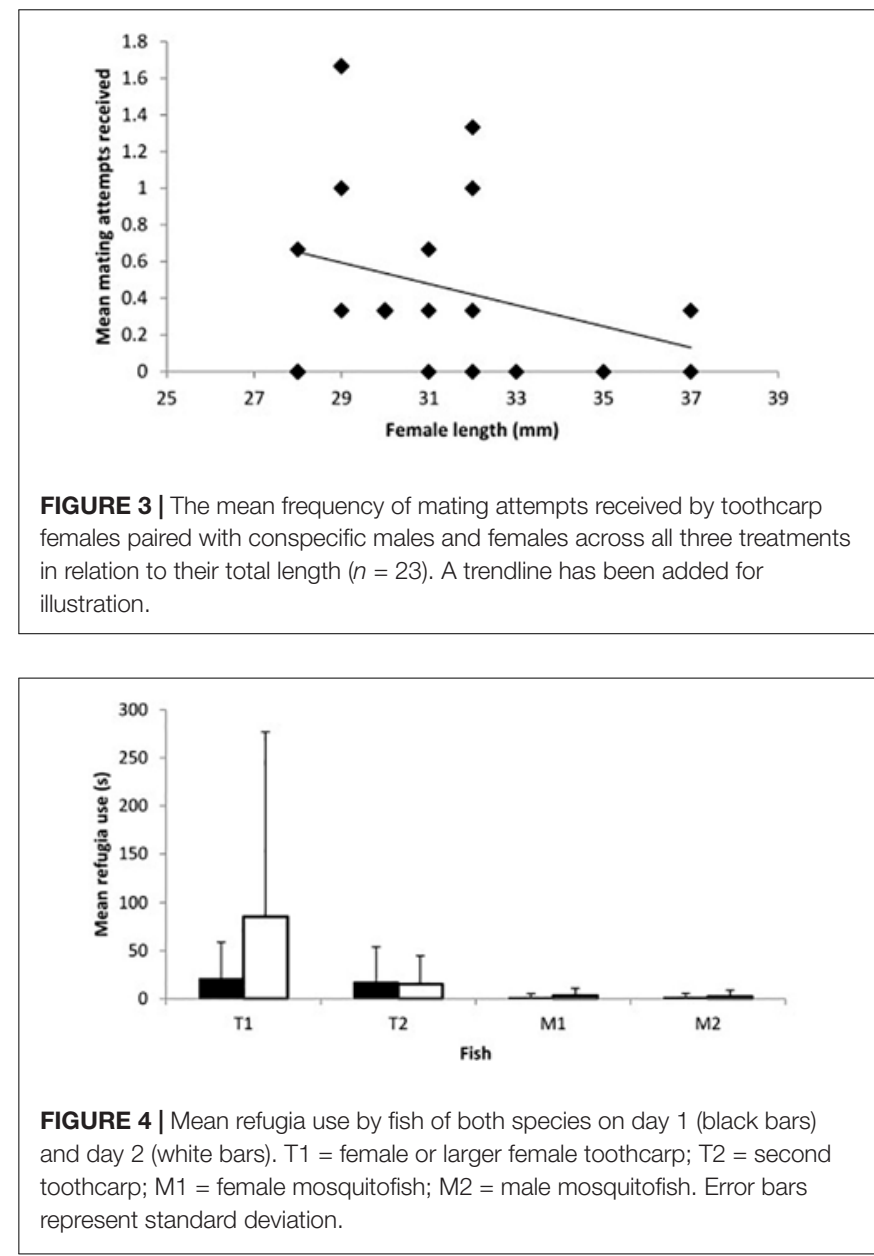

All male mosquitofish in this study were "normal" males in that all were sexually mature and had previous access to females of their own species so were presumably sexually experienced. Therefore, these results cannot be explained by sexual naivety. However, as mosquitofish males and females were housed together but separately from toothcarp, it is conceivable that this is an extreme case of preference for novel or unfamiliar individuals (Kelley et al., 1999) but even if this was the case, 
male toothcarp were still treated differently. It is also possible that female toothcarp were not as proficient at avoiding mating attempts as male toothcarp and female mosquitofish. However, male toothcarp also harass females of their species and females are adept at avoiding this harassment either through escape or aggression (KM pers. obs.) so this is unlikely. Finally, fish may shoal together based on similarities in, e.g., activity types or habitat preferences as much as through conspecific attraction (Ward et al., 2020). As conspecifics are likely to be most similar in these respects, male mosquitofish may have considered any individual in their vicinity to be a conspecific, but again, male toothcarp did not receive the same attention as females. Whatever factors are involved it is clear that male mosquitofish differentiated between male and female toothcarp and initially attempted to interact with female toothcarp as they would females of their own species.

Male mosquitofish did, however, direct their mating attempts more accurately by the second day. Neither morphology (Meffe and Snelson, 1989; Evans et al., 2011) nor pheromone production (Burnard et al., 2008), both factors in mate preference, are likely to have changed substantially within this time, and while female behavior may have been modified this was not particularly apparent (KM pers. obs.). Although, mating attempts received by females of each species still did not differ significantly, there was an obvious trend in the data and it is likely that with slightly more time mosquitofish males would learn to direct their mating attempts exclusively toward mosquitofish females. Recognition of both sexes within an individual's species as a unified category separate from heterospecifics, and differentiating between species within a single sex, are distinct concepts (Mendelson and Shaw, 2012). Our results indicate that for male mosquitofish either sex differentiation takes priority over species differentiation or they are able to differentiate between the sexes more readily than they are able to differentiate between species. Mating decisions are hierarchical processes in which mate choice is based first on compatibility and then evaluation of other quality indicators (Mendelson and Shaw, 2012). For mosquitofish males it appears that compatible is synonymous with female, and quality assessment entails selecting the correct type of female. A similar delay in species recognition has been shown in another Poeciliid fish, the guppy, Poecilia reticulata, in which males initially attempted cross species matings with the swamp guppy, Poecilia picta (Magurran and Ramnarine, 2004, 2005) and the Goodeid, Skiffia bilineata (Valero et al., 2008, 2009) before targeting their own species. However, in these studies sex recognition was assumed rather than tested. Whatever the exact chronological recognition sequence, male mosquitofish did begin to discriminate between con- and heterospecific females by the second day. It is interesting that there appeared to be an increase in discrimination against larger toothcarp females that are probably more morphologically similar to mosquitofish females than smaller toothcarp, suggesting that male mosquitofish were learning to differentiate between these comparable phenotypes.

How do these results elucidate the mechanisms by which mosquitofish males select suitable mates? Mate acceptance thresholds may be adjusted based on the costs of heterospecific matings, the frequency of interactions with heterospecifics and the benefits of conspecific matings (Pfennig, 1998) so an individual may attempt to mate with individuals of several different species. In the normal course of events, a (usually) male will solicitate a mating with a female, the female will reciprocate resulting in positive reinforcement (Krebs and Davies, 1993), and the male will associate that phenotype with successful mating, thus learning positive recognition of potential mates. Avoidance of heterospecifics will be facilitated by negative experiences such as rejection by heterospecific females or aggression from males (Verzijden et al., 2012). However, for mosquitofish with a coercive mating system (Meffe and Snelson, 1989; Evans et al., 2011), the usual female response to a solicited mating attempt is rejection. Indeed, in this study there were no observations of consensual mating between male and female mosquitofish. Moreover, males do not engage in energetically expensive displays, provide no nuptial gifts, and undergo no sperm transfer without full copulation (Evans et al., 2011), so the costs of mating attempts comprise only energy and time used in pursuit of females. Male mosquitofish may therefore be selected for persistence despite rejection, thus negating heterospecific avoidance though negative experiences.

For male mosquitofish it may be more cost effective to learn who not to mate with, i.e., negative recognition. Mate recognition is a behavioral response indicating that one individual considers another an appropriate mate, even if mistakenly (Ryan and Rand, 1993) and there are many cases of adaptive hybridization (Arnold and Hodges, 1995; Mallet, 2007; Mendelson and Shaw, 2012) so other species may also form part of the available pool of potential mates. A single species may overlap with a mosaic of other species across its entire geographic range (Hoskin and Higgie, 2010; Camacho-Cervantes et al., 2014) and for the highly invasive mosquitofish this state is intensified. As potential mates are a subset of the taxonomic species of an organism, but also of the whole ecological community (Mendelson and Shaw, 2013), for mosquitofish the pool of potential mates can be considered to be global. The form of recognition that is prioritized (in this case sex or species) depends on the likelihood of making a mistake in recognition and the fitness costs of doing so (Pfennig, 1998). If mosquitofish males can recognize any single species as being unsuitable mates, this cuts out just a small proportion of the potential mate pool. However, if males can distinguish sexes and recognize females as potential mates, fully $50 \%$ of the potential mate pool will be excluded. Thus, for mosquitofish it may be more beneficial to prioritize sex recognition, and subsequently learn to avoid the particular species with which it interacts at any given location. This further suggests that sex recognition is innate in this species, whereas species recognition is learned. These findings may play a role in mosquitofish success as an invader.

The initiation of learned recognition was remarkably rapid in this study, occurring within $24 \mathrm{~h}$. Rapid learning has also been demonstrated in an invasive population of the closely related G. affinis, which showed significant improvement in food location ability within 3 days (Magellan et al., 2019). However, previous mate recognition studies using the guppy have shown no recognition of heterospecific S. bilineata females within 3 days (Valero et al., 2008); recognition of P. picta females after four (Magurran and Ramnarine, 2004) 
and six (Magurran and Ramnarine, 2005) days; and individual recognition of conspecific (Griffiths and Magurran, 1997) and heterospecific (Valero et al., 2009) individuals after 12 and 14 days, respectively. It may be that the distance between these species is a factor in the speed of learning (Mendelson and Shaw, 2012). In comparison to the mosquitofish-toothcarp model system, the species used in the above studies are much more similar. In common with mosquitofish, the Poeciliids ( $P$. reticulata and $P$. picta) and $S$. bilineata are native to nearby areas and have comparable mating systems (Parenti, 1981; Meffe and Snelson, 1989; Evans et al., 2011), whereas toothcarp belongs to a group which diverged much earlier (Parenti, 1981). The marked differences between mosquitofish and toothcarp, particularly in mating system, may provide superior information by which recognition learning can occur. This capacity for rapid learning may be a factor in (e.g., Roudez et al., 2008), or an effect of Payne et al. (2004), the invasive success of mosquitofish (Magellan et al., 2019). They have been introduced to many new environments and therefore potentially exposed to many new heterospecifics. As discussed above, the costs to mosquitofish of misplaced mating attempts are relatively minor. Injury through aggressive interactions, while not likely with toothcarp, may be an additional cost in other situations. The ability to rapidly learn recognition may help to minimize these costs and so predispose mosquitofish to be a successful invader.

These findings may have wider implications. Recognition is defined as the ability to distinguish something, such as another individual, and to produce a distinct and quantifiable response. Recognition of a diverse variety of entities may be necessary during an individual's lifetime, from recognition of mates, through predator recognition, to recognition of suitable habitats or environmental features. In all cases, recognition necessitates the abilities to remember particular signals and to discriminate them from other signals (ten Cate and Rowe, 2007); and the same or different signals may be recognized in different contexts (Okamoto and Grether, 2013). This suggests a number

\section{REFERENCES}

Andersson, M. (1994). Sexual Selection. Princeton, USA: Princeton University Press.

Arnold, M. L., and Hodges, S. A. (1995). Are natural hybrids fit or unfit relative to their parents? Trends Ecol. Evol. 10, 67-71. doi: 10.1016/s0169-5347(00)8 8979-x

Benejam, L., Alcaraz, C., Sasal, P, Simon-Levert, G., and García-Berthou, E. (2009). Life history and parasites of the invasive mosquitofish (Gambusia holbrooki) along a latitudinal gradient. Biol. Inv. 11, 2265-2277. doi: 10.1007/s10530-0089413-0

Burnard, D., Gozlan, R. E., and Griffiths, S. W. (2008). The role of pheromones in freshwater fish. J. Fish Biol. 73, 1-16. doi: 10.1111/j.1095-8649.2008.01872.x

Camacho-Cervantes, M., Ojanguren, A. F., Deacon, A. E., Ramnarine, I. W., and Magurran, A. E. (2014). Association tendency and preference for heterospecifics in an invasive species. Behaviour 151, 769-780. doi: 10.1163/1568539x00003169

Campobello, D., and Sealy, S. G. (2011). Use of social over personal information enhances nest defence against avian brood parasitism. Behav. Ecol. 22, 422-428. doi: 10.1093/beheco/arq225 of questions. For example, how long is learned recognition by mosquitofish retained? What recognition mechanisms are used to ensure recognition is accurate? Is recognition specific to a single species or context or can it be generalized to other species or contexts, such as from mating to competition? These questions provide potential areas of future research in studies of learning, recognition and particularly for invasive mosquitofish.

\section{DATA AVAILABILITY STATEMENT}

The raw data supporting the conclusions of this article will be made available by the authors, without undue reservation.

\section{AUTHOR CONTRIBUTIONS}

KM conceived, designed, and carried out the experiment, and took the lead on data analysis and manuscript preparation. EG-B consulted throughout. Both authors collaborated on writing and approved the submission.

\section{FUNDING}

This research was supported by a Marie Curie International Reintegration Grant within the 7th European Community Framework Program (KM). Additional financial support was provided by the Spanish Ministry of Science (projects CGL200912877-C02-01, CSD2009-00065, and PID2019-103936GB-C21).

\section{ACKNOWLEDGMENTS}

We wish to thank all members of the GRECO group who assisted at different points in this project. Sincere thanks to the referees and editors whose contribution helped improve this manuscript.

Candolin, U. (2003). The use of multiple cues in mate choice. Biol. Rev. 78, 575-595. doi: 10.1017/s1464793103006158

Doadrio, I. (ed.) (2002). Atlas y Libro Rojo de Los Peces Continentales de España. Madrid: Ministerio de Medio Ambiente.

Epp, K. J., and Gabor, C. R. (2008). Innate and learned predator recognition mediated by chemical signals in Eurycea nana. Ethology 114, 607-615. doi: 10.1111/j.1439-0310.2008.01494.x

Evans, J. P., Pilastro, A., and Schlupp, I. (eds) (2011). Ecology and Evolution of Poeciliid Fishes. Chicago: University of Chicago Press.

Freyhof, J., and Brooks, E. (2011). European Red List of Freshwater Fishes. Luxembourg: Publications Office of the European Union.

Galef, B. G., and Laland, K. N. (2005). Social learning in animals: empirical studies and theoretical models. BioScience 55, 489-499. doi: 10.1641/0006-3568(2005) 055[0489:sliaes]2.0.co;2

García-Berthou, E., Alcaraz, C., Pou-Rovira, Q., Zamara, L., Coenders, G., and Feo, C. (2005). Introduction pathways and establishment rates of invasive aquatic species in Europe. Can. J. Fish. Aquat. Sci. 62, 453-463. doi: 10.1139/ f05-017

Griffiths, S. W., and Magurran, A. E. (1997). Familiarity in schooling fish: how long does it take to acquire? Anim. Behav. 53, 945-949. doi: 10.1006/anbe.1996.0315 
Hoskin, C. J., and Higgie, M. (2010). Speciation via species interactions: the divergence of mating traits within species. Ecol. Lett. 13, 409-420. doi: 10.1111/ j.1461-0248.2010.01448.x

Irwin, D. E., and Price, T. (1999). Sexual imprinting, learning and speciation. Heredity 82, 347-354. doi: 10.1038/sj.hdy.6885270

Kamo, M., Ghirlanda, S., and Enquist, M. (2002). The evolution of signal form: effects of learned versus inherited recognition. Proc. R. Soc. Lond. B 269, 1765-1771. doi: 10.1098/rspb.2002.2081

Kelley, J. L., Graves, J. A., and Magurran, A. E. (1999). Familiarity breeds contempt in guppies. Nature 401, 661. doi: 10.1038/44314

Krebs, J. R., and Davies, N. B. (1993). An Introduction to Behavioural Ecology, 3rd Edn. Oxford: Blackwell Science.

Lever, C. (1996). Naturalized Fishes of the World. London: Academic Press.

Lowe, S., Browne, M., Boudjelas, S., and De Poorter, M. (2000). 100 of the World's Worst Invasive Alien Species: A Selection from the Global Invasive Species Database. Auckland: Invasive Species Specialist Group.

Magellan, K., Bonebrake, T. C., and Dudgeon, D. (2019). Temperature effects on exploratory behaviour and learning ability of invasive mosquitofish. Aquat. Inv. 14, 502-517. doi: 10.3391/ai.2019.14.3.09

Magellan, K., and García-Berthou, E. (2015). Influences of size and sex on invasive species aggression and native species vulnerability: a case for modern regression techniques. Rev. Fish Biol. Fisher. 25, 537-549. doi: 10.1007/s11160-015-9391-0

Magellan, K., and García-Berthou, E. (2016). Experimental evidence for the use of artificial refugia to ameliorate the impacts of invasive Gambusia holbrooki on an endangered fish. Biol. Invasions 18, 873-882. doi: 10.1007/s10530-016-1057-x

Magurran, A. E., and Ramnarine, I. W. (2004). Learned mate recognition and reproductive isolation in guppies. Anim. Behav. 67, 1077-1082. doi: 10.1016/ j.anbehav.2003.10.010

Magurran, A. E., and Ramnarine, I. W. (2005). Evolution of mate discrimination in a fish. Curr. Biol. 15, R868-R869.

Mallet, J. (2007). Hybrid speciation. Nature 446, 279-283.

Meffe, G. K., and Snelson, F. F. (1989). The Ecology and Evolution of Live Bearing Fishes. New Jersey: Prentice Hall.

Mendelson, T. C., and Shaw, K. L. (2012). The (mis)concept of species recognition. Trend. Ecol. Evol. 27, 421-427. doi: 10.1016/j.tree.2012.04.001

Mendelson, T. C., and Shaw, K. L. (2013). Further misconceptions about species recognition: a reply to Padian and Horner. Trend. Ecol. Evol. 28, 252-253. doi: 10.1016/j.tree.2013.02.012

Milet-Pinheiro, P., Ayasse, M., Schlindwein, C., Dobson, H. E. M., and Dötterl, S. (2012). Host location by visual and olfactory floral cues in an oligolectic bee: innate and learned behavior. Behav. Ecol. 23, 531-538. doi: 10.1093/beheco/ $\operatorname{arr} 219$

Mueller, T., O’Hara, R. B., Converse, S. J., Urbanek, R. P., and Fagan, W. F. (2013). Social learning of migratory performance. Science 341, 999-1002. doi: $10.1126 /$ science. 1237139

Okamoto, K. W., and Grether, G. F. (2013). The evolution of species recognition in competitive and mating contexts: the relative efficacy of alternative mechanisms of character displacement. Ecol. Lett. 16, 670-678. doi: 10.1111/ele.12100

Parenti, L. R. (1981). A phylogenetic and biogeographic analysis of cyprinodontiform fishes (Teleostei, Atherinomorpha). Bull. Am. Mus. Nat. Hist. 168, 335-557.
Payne, C. M., Tillberg, C. V., and Suarez, A. V. (2004). Recognition systems and biological invasions. Ann. Zool. Fennici 41, 843-858.

Pfennig, K. S. (1998). The evolution of mate choice and the potential for conflict between species and mate quality recognition. Proc. R. Soc. Lond. B 265, 1743-1748. doi: 10.1098/rspb.1998.0497

Pyke, G. H. (2008). Plague minnow or mosquito fish? A review of the biology and impacts of introduced Gambusia species. Ann. Rev. Ecol. Evol. Syst. 39, 171-191. doi: 10.1146/annurev.ecolsys.39.110707.173451

Roudez, R. J., Glover, T., and Weis, J. S. (2008). Learning in an invasive and a native predatory crab. Biol. Inv. 10, 1191-1196. doi: 10.1007/s10530-007-9195-9

Ruiz Navarro, A., and Oliva Paterna, F. J. (2012). "Fartet - Aphanius iberus," in Enciclopedia Virtual de los Vertebrados Españoles, eds A. Salvador and B. Elvira (Madrid: Museo Nacional de Ciencias Naturales).

Ryan, M. J., and Rand, A. (1993). Species recognition and sexual selection as a unitary problem in animal communication. Evolution 47, 647-657. doi: 10. 1111/j.1558-5646.1993.tb02118.x

Sherman, P. W., Reeve, H. K., and Pfennig, D. W. (1997). "Recognition systems," in Behavioural Ecology: An Evolutionary Approach, 4th Edn, eds J. R. Krebs and N. B. Davies (Oxford: Blackwell Science), 69-96.

Sih, A., Bolnick, D. I., Luttberg, B., Orrock, J. L., Peacor, S. D., Pintor, L. M., et al. (2010). Predator-prey naïveté, antipredator behavior, and the ecology of predator invasions. Oikos 119, 610-621. doi: 10.1111/j.1600-0706.2009.18039.x

Strauss, S. Y., Lau, J. A., and Carroll, S. P. (2006). Evolutionary responses of natives to introduced species: what do introductions tell us about natural communities? Ecol. Lett. 9, 357-374. doi: 10.1111/j.1461-0248.2005. 00874.x

ten Cate, C., and Rowe, C. (2007). Biases in signal evolution: learning makes a difference. Trend. Ecol. Evol. 22, 380-387. doi: 10.1016/j.tree.2007.03.006

Valero, A., Macías Garcia, C., and Magurran, A. E. (2008). Heterospecific harassment of native endangered fishes by invasive guppies in Mexico. Biol. Lett. 4, 149-152. doi: 10.1098/rsbl.2007.0604

Valero, A., Magurran, A. E., and Macías Garcia, C. (2009). Guppy males distinguish between unfamiliar females of a distantly related species. Anim. Behav. 78, 441-445. doi: 10.1016/j.anbehav.2009.05.018

Verzijden, M. N., ten Cate, C., Servidio, M. R., Kozak, G. M., Boughman, J. W., and Svensson, E. I (2012). The impact of learning on sexual selection and speciation. Trends. Ecol. Evol. 27, 511-519.

Ward, A. J. W., Kent, M. I. A., and Webster, M. M. (2020). Social recognition and social attraction in group-living fishes. Front. Ecol. Evol. 8:15. doi: 10.3389/fevo. 2020.00015

Conflict of Interest: The authors declare that the research was conducted in the absence of any commercial or financial relationships that could be construed as a potential conflict of interest.

Copyright (c) 2021 Magellan and García-Berthou. This is an open-access article distributed under the terms of the Creative Commons Attribution License (CC BY). The use, distribution or reproduction in other forums is permitted, provided the original author(s) and the copyright owner(s) are credited and that the original publication in this journal is cited, in accordance with accepted academic practice. No use, distribution or reproduction is permitted which does not comply with these terms. 